\title{
Object-based Integrated Landscape Change Analysis: synergy of multi-temporal LiDAR and very high resolution orthophotos
}

\author{
M. Kamps ${ }^{\text {a }}$, A.C. Seijmonsbergen ${ }^{\text {a }}$ and W. Bouten ${ }^{\mathrm{a}}$ \\ aIBED, Institute for Biodiversity and Ecosystem Dynamics (IBED) - martijntkamps@ gmail.com - (a.c.seijmonsbergen, \\ w.bouten)@uva.nl
}

KEY WORDS: Data Synergy, OBIA, Landslide, Above Ground Biomass, LiDAR, Orthophotos, Land Cover Change

\begin{abstract}
:
Active landslides have three major effects on a landscape: 1. land cover change, 2. topographical change, and 3. above ground biomass change. Data derived from multi-temporal Light Detection and Ranging technology (LiDAR) is used in combination with multi-temporal orthophotos to quantify changes between 2006 and 2012, caused by a landslide near Doren in Austria. Data synergy is used to optimize accuracies of land cover change, and to improve results of topographical change analysis and aboveground biomass estimations. Topographical change is calculated using differencing of digital terrain models. The above ground biomass is quantified by applying a local-maximum algorithm for tree top detection, in combination with allometric equations. The land cover change classification accuracies were improved from 65\% (using only LiDAR) and 76\% (using only orthophotos) to 90\% (using synergy) for 2006. A similar increase from respectively $64 \%$ and $75 \%$ to $91 \%$ was established for 2012 . The results of the improved land cover classifications were used to optimize the topographical and above ground biomass change calculations. Fine-scale improvements of the classifications included forest edges and shadows, small open spots in the vegetation, and confusion between land cover classes. The enhanced accuracies of the land cover change analysis demonstrate the effectiveness and advantages of using synergy of LiDAR and orthophotos using OBIA. The method has great potential to be transferred to larger areas for use in monitoring, although data size calls for workflows to operate on cloud-based infrastructures that provide sufficient computational power.
\end{abstract}

\section{INTRODUCTION}

The synergy of very high resolution (VHR) imagery such as orthophotos and data derived from Light Detection and Ranging (LiDAR) technology to detect land cover change (LCC), topographical and above ground biomass (AGB) changes through object-based image analysis (OBIA) in an area affected by an active landslides is analyzed. Landslides are common processes that may cause continuous or sudden changes in the topography and the overlying vegetation cover. The growing availability of multi-temporal LiDAR-based elevation data facilitates the combined analysis of fine-scale 3D topographical and forest structure changes occurring in landslide areas.

OBIA has been successfully applied in the segmentation and classification of VHR imagery for mapping LCC change (Machala \& Zejdova, 2014; Zhou et al, 2008) and in many landslide detection studies (Lahousse et al. 2011, Li et al. 2015). In such cases, OBIA generally outperforms pixel-based approaches in LCC studies (Machala \& Zejdova, 2014), although hybrid approaches (Aguirre-Gutierrez et al. 2012, Wang, 2004) may sometimes lead to better accuracies. The synergy between VHR imagery and LiDAR information has been used to analyze 3D-forest structure (Machala \& Zejdova, 2014), to monitor forest canopy height (Wulder \& Seemann, 2003) and to classify land cover (Mücher et al., 2015; Parent et al., 2015). These studies mention LCC classification accuracies of more than eighty percent and emphasize the mutual benefits of the combination of VHR imagery and LiDAR. In addition, embedding elevation data into LCC change detection is also thought to improve the accuracy of segmentation and classification (Desclee et al., 2006). The forest cover in a landslide area can not only be expressed in areal loss, but can also be characterized by changes in AGB, by using tree specific allometric relations derived from multi-temporal LiDAR-based canopy height models (Muukkonen et al., 2005).
LiDAR-based DTM differencing (James et al. 2012) may reveal detailed changes in topography of forested and non-forested parts of the landslide and may aid interpretation of landslide development and its relation to event-based loss of trees. These trends show that the combination of VHR imagery, LiDARbased elevation models and OBIA may result in higher accuracies in change analyses studies. To integrate the various analysis techniques, we present a combined approach using a modular workflow in the commercial eCognition 9.2 software package that automatically analyzes LCC change, and, for the same time frame, quantifies the topographical and the AGB changes of an active landslide near the village of Doren in Vorarlberg, western Austria.

\section{STUDY AREA}

The landslide near Doren is located in the north of Vorarlberg along the river Weißach and is known to be active since 1847 (Fig 1.). Major events occurred in the early 1927, 1935 and 1988 , during which $2-3 \times 10^{6} \mathrm{~m}^{3}$ was mobilized as rock- and soil slides, and debris flows (Jaritz and Marte, 2008). The geology is formed by a tilted sedimentary sequence of alternating Molasse marls, sandstone and conglomerates (Friebe, 2007), that, in combination with a highly fractured rock mass, promotes groundwater flow to potential failure planes, thus reactivating the landslide. The rock underlain area was glacially eroded and covered by $5-10 \mathrm{~m}$ of subglacial till, which was dissected again by the approximately 80 deep valley of the Weißach River. Norway spruce is the dominant tree species on the valley slopes with understory of shrubs and many small, open spots, while meadows (grass), shrubs and some infrastructure are present in the upper, intact low-angle slopes. 


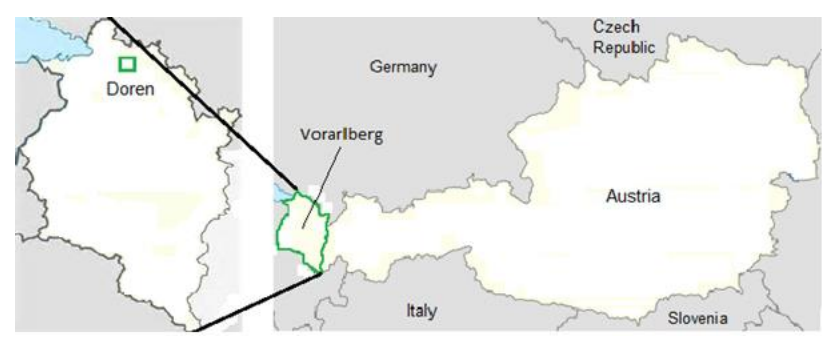

Figure 1. Location of the Doren landslide (coordinates: $47^{\circ} 29^{\prime} 31.9^{\prime \prime} \mathrm{N} 9^{\circ} 52^{\prime} 55.6^{\prime \prime E}$ ) in Vorarlberg, western Austria.

\section{METHODS}

\subsection{Data}

In table 1 metadata of the true colour orthophotos (TCO) and LiDAR data for 2006 and 2012 are presented.

\begin{tabular}{|c|c|c|c|c|}
\hline Year & Data type & Extension & Camera & Accuracy \\
\hline \multirow[t]{2}{*}{2006} & TCO & img & Zeiss RMK TOP $30 / 23$ & Resolution: $0,125 \mathrm{~m} \times 0,125 \mathrm{~m}$ \\
\hline & LIDAR & img & ALTM 2050 & $\begin{array}{l}\text { Point density: } 2 / \mathrm{m} 2 \\
\text { Height accuracy: } 0,1 \mathrm{~m} \\
\text { Location accuracy: } 0,2 \mathrm{~m} \\
\text { Vertical accuracy: }<0,25 \mathrm{~m} \\
\text { Horizontal accuracy: }<0,30 \mathrm{~m}\end{array}$ \\
\hline \multirow[t]{2}{*}{2012} & TCO & .img & Vexcel Ultracam XP RGBI & Resolution: 0,125 $\mathrm{m} \times 0,125 \mathrm{~m}$ \\
\hline & LIDAR & laz & $\begin{array}{l}\text { Harrier 56-009 } \\
\text { LiDAR System }\end{array}$ & $\begin{array}{l}\text { Point density: } 4 \text { to } 8 / \mathrm{m} 2 \\
\text { Height accuracy: } 0,075 \mathrm{~m} \\
\text { Location accuracy: } 0,1 \mathrm{~m} \\
\text { Vertical accuracy: }<0,15 \mathrm{~m} \\
\text { Horizontal accuracy: }<0,25 \mathrm{~m}\end{array}$ \\
\hline
\end{tabular}

Table 1. Metadata of the various datasets

\subsection{Workflow}

Figure 2 shows the workflow used to determine LCC change, topographical change and AGB change. The workflow consists of main procedures $(1-4)$ which have been broken down into several steps (A - D). To compare the added value of using data synergy instead of an individual dataset, three scenarios were calculated, indicated by coloured arrows. The 'synergy' scenario is indicated by a green arrow, while the 'orthophotos only' and the 'LiDAR data only' scenarios are indicated by blue and red arrows respectively.

\subsubsection{Data Pre-processing}

The LAStools extension for ArcGIS was used to interpolate the 2012 point-cloud LiDAR data (Rapidlasso $\mathrm{GmbH}$ ). In eCognition the maximum first return and minimum last return were used to filter out the DTM and DSM respectively.

\subsubsection{Land Cover Change detection}

The following land-cover classes that have been recognized and used in the LCC are: bare soil, grass and shrub land, forest, water, road and buildings. Three scenarios have been processed: one using segmentation and classification synergy of the orthophotos and LiDAR datasets and two scenarios using only the orthophotos and only the LiDAR data. The general procedures and steps of segmentation, classification, accuracy assessment and image differencing is described in four subsections (see also Figure 2).

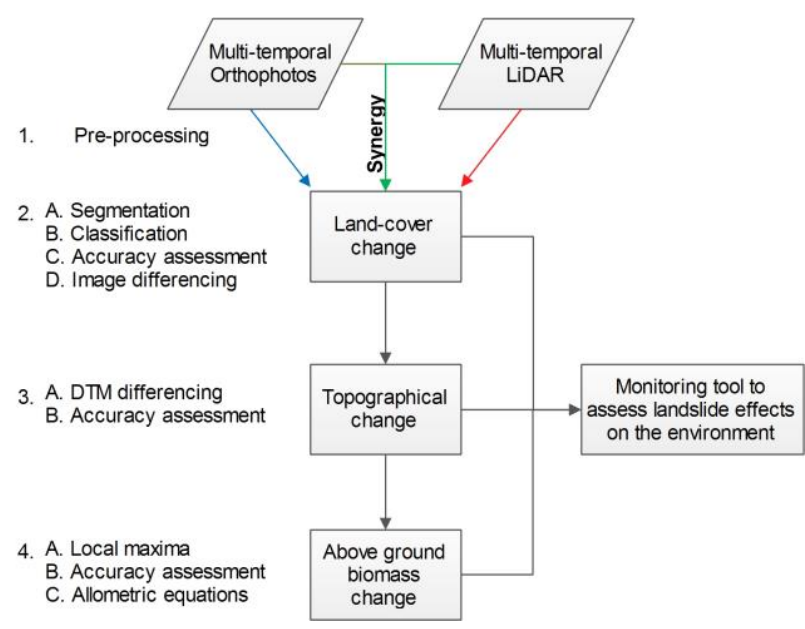

Figure 2. Workflow, in which he 'synergy' scenario is indicated by a green arrow, the 'orthophotos only' and the 'LiDAR data only' scenarios are indicated by blue and red arrows.

Step A. Following successful applications of multiresolution segmentation (MRS) in mountainous environments (AguirreGutierrez et al., 2012; Anders et al, 2013; Eisank et al., 2014) an iterative algorithm was developed producing 125 parameter combinations, similarly to the work of Clinton et al. (2010). The parameter settings used for scale parameter are 10, 20, 30, 40 and 50, for the shape parameter $0.1,0.3,0.5,0.7,0.9$ and for compactness $0.1,0.3,0.5,0.7$ and 0.9 . The accuracy of the segmentation results was determined by comparing the generated objects with the orthophotos based on over-and under segmentation (Esch et al., 2008). Based on the accuracy assessment a MRS using a scale parameter of 50, a shape parameter of 0.3 and compactness of 0.5 , and the spectral information from the orthophotos in combination with the LiDAR-derived canopy height model (CHM) was used.

Step B. The classification consists of two routines: (1) a stratified membership classification based on feature space optimization (FSO) and (2) fuzzy-logic improvements based on context, geometry, spectral and elevation characteristics.

1. For the FSO 200 samples per land-cover class were manually classified based on orthophoto recognition. FSO was then applied to twelve distinct features derived from both the orthophotos and LiDAR.

2. Fuzzy-logic rulesets are used to improve the classification accuracy after membership-based classification. This step is necessary since the overlap of the orthophotos and LiDAR introduces some fine-scale errors, for instance shadowing effects, small open spots in the forest and mismatches between bare soil and the LiDAR model. Fuzzy-logic rulesets that use the spectral characteristics (RGB), elevation information (LiDAR) and contextual information derived from expert knowledge can deal with such errors. These detailed rulesets are specifically used to improve finescale features, optimize classification borders and shadows and minimize errors as a result of dataset overlap.

Step C. Classification accuracy assessment was performed by random selection of 250 objects. A standard confusion error matrix was derived including user and producer accuracies according to the method described by Congalton (1991).

Step D. After image classification post-classification change detection is applied using simple image differencing (Gutierrez 
et al., 2012; Zhou et al., 2008).

\subsubsection{Topographical change}

The topographical change procedure was calculated in two steps (Figure 2).

Step A. The topographical volumetric change was calculated for each land cover class using DTM differencing and multiplying with pixel size.

Step B. Following Wheaton et al. (2009) the propagation error in the DTM differencing process caused uncertainties of 0.29 meters. This represents $0.0066 \mathrm{~m}^{3}$ per pixel volumetric change. Therefore, volumetric changes $<0.01 \mathrm{~m}^{3}$ are disregarded and considered as 'no change areas' to reduce apparent change as a result of data errors (Latypov, 2002).

\subsubsection{Above Ground Biomass change}

The AGB change procedure was calculated in three steps (Figure 2).

Step A. The eCognition local-maxima algorithm was used on the CHM to derive canopy top locations. The local maximum algorithm was applied to areas which were classified as forest with the synergy approach for LCC.

Step B. Accuracy assessment of the canopy tops is performed by manual inspection and comparison of the generated canopy tops with the CHM and orthophotos.

Step C. According to Maier et al. (2006) the Norway Spruce, is the dominant tree species in Vorarlberg. Therefore, the allometric equations for biomass calculation as used by Muukkonen et al. (2005) for Norway Spruce were used:

$$
\mathrm{DBH}=\mathrm{e}^{\left(\left(0.1687+1.2413^{*} \ln ([\mathrm{H}])\right)\right.}
$$

where

$$
\begin{aligned}
& \mathrm{DBH}=\text { diameter at breast height } \\
& \mathrm{H}=\text { tree height }
\end{aligned}
$$

$$
\mathrm{B}=\mathrm{e}^{\left(-4.63873+\left(2.75352 * \ln ([\mathrm{DBH}])-0.08578^{*} \ln ([\mathrm{H}])\right)\right)}
$$

where $\quad \mathrm{B}=$ biomass

The allometric equations are used to first calculate the diameter at breast height $[\mathrm{R} 2=0,880]$ and subsequently the biomass using the height of the canopy tops [R2 $=0,946]$.

\section{RESULTS}

\subsection{Land Cover Change}

Although the segmentation results using the synergy between the datasets could not be quantified, manual inspection reveals that segmentation results improved. Segmentation based solely on the orthophotos shows under segmentation of spectrally similar adjacent land-cover classes, while segmentation based solely on LiDAR-derived data does not distinguish between spectrally different land-cover classes with similar elevation characteristics.

Classification results were substantially improved using the synergy between the datasets. The highest overall accuracy of the classification based on orthophotos only was 76\% (kappa: 0.64 ), for classification based only on LiDAR-derived data $65 \%$ (kappa: 0.46) and for the synergy based classification $91 \%$ (kappa: 0.93). Table 2 shows the confusion matrix for classification based on orthophotos and LiDAR in 2012.

\begin{tabular}{|l|r|r|r|r|r|r|r|}
\hline $\begin{array}{l}\text { Confusion } \\
\text { Matrix }\end{array}$ & Bare soil & Building & Grassland & Road & Trees & Water & \multicolumn{1}{c|}{ Sum } \\
\hline Bare soil & 36 & 0 & 1 & 1 & 1 & 0 & 39 \\
Building & 0 & 5 & 0 & 0 & 0 & 0 & 5 \\
Grassland & 2 & 0 & 63 & 1 & 6 & 0 & 72 \\
Road & 2 & 0 & 1 & 12 & 0 & 0 & 15 \\
Trees & 1 & 0 & 4 & 1 & 117 & 0 & 123 \\
Water & 2 & 0 & 0 & 0 & 0 & 11 & 13 \\
sum & 43 & 5 & 69 & 15 & 124 & 11 & 267 \\
& & & & & & & \\
Producer & 0,84 & 1,00 & 0,91 & 0,80 & 0,94 & 1,00 & \\
User & 0,92 & 1,00 & 0,88 & 0,80 & 0,95 & 0,85 & \\
Overall & 0,91 & & & & & & \\
accuracy & 0,93 & & & & & & \\
Kappa & & & & & & \\
statistic & 0, & & & & & & \\
\hline
\end{tabular}

Table 2. Classification accuracies for 2012

Compared to classifications solely based on membership functions, the fuzzy-logic based stratified classifications improved the accuracy results with $26 \%$ (for 2006) and $18 \%$ (for 2012).

Classification based solely on orthophotos may result in confusion between forest and grassland and classification based solely on LiDAR may cause confusion between grassland and bare soil. Orthophoto-based classification does however separate grassland with bare soil, while LiDAR-based classification separates forests from grassland and bare soil. The spectral and elevation synergy between the datasets therefore results in accurate classification of all land-use classes. Two examples of classification improvements are presented in figure 3.
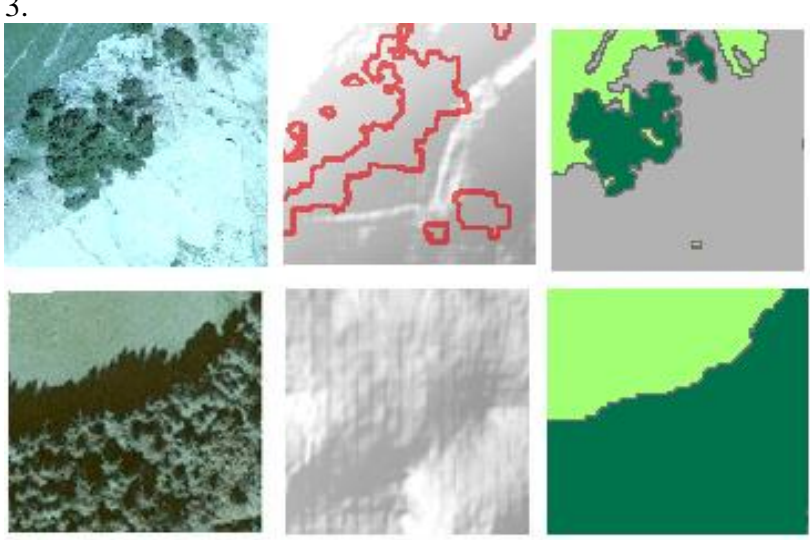

Elevation [m]

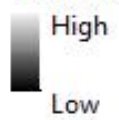

Trees

Grassland

Bare soil

LIDAR error

Figure 3. Two examples of classification improvements using data synergy. The left column shows the orthophoto fragments, the central the LiDAR hillshade and indicated error in red. The right column displays the improved classification result.

In the left column the orthophoto is presented, in the central column the LiDAR dataset and errors indicated in red and in the right column the improved classification result. LiDAR-based errors refer to areas with a CHM higher $>2$ meters, but without vegetation on the orthophotos. These were correctly classified as bare soil using spectral information. The shadow areas in were correctly classified as grassland using LiDAR derived elevation information. 
In table 3 the LCC changes for each land-cover class from 2006 to 2012 are summarized.

\begin{tabular}{|c|c|c|c|c|c|c|c|c|}
\hline Year & & Bare soil & Building & Grass & Road & Trees & Water & Total \\
\hline \multirow[t]{2}{*}{2006} & Sum $[\mathrm{m} 2]$ & |52484,3 & $\begin{array}{l}680,2 \\
\end{array}$ & 86111,4 & N.A. & 241721,6 & 1552,3 & 382549,9 \\
\hline & Percent [\%] & 13,7 & 0,2 & 22,5 & N.A. & 63,2 & 0,4 & \\
\hline \multirow[t]{2}{*}{2012} & Sum [m2] & 41458,0 & 532,7 & 92694,4 & 2364,2 & 244386,0 & 1114,6 & \\
\hline & Percent [\%] & 10,8 & 0,1 & 24,2 & 0,6 & 63,9 & 0,3 & \\
\hline 2006-2012 & Change [\%] & $-2,9$ & $-0,1$ & 1,7 & 0,6 & 0,7 & $-0,1$ & \\
\hline
\end{tabular}

Table 3. Quantification of relative LCC per land-cover class.

Table 4 summarizes the 'from-to' changes between 2006 and 2012. A map of these changes in presented in Figure 4, upper left panel, in relation to the landslide area and surroundings.

\begin{tabular}{|c|c|c|c|c|c|c|}
\hline & GtG & GtB & GtT & GtR & BtB & BtG \\
\hline Sum [m2] & 51405 & 10274,07 & 23078,65 & 1287,33 & 24773,08 & 22204,76 \\
\hline Change [\%] & 13,44 & 2,69 & 6,03 & 0,34 & 6,48 & 5,81 \\
\hline & BtT & BtR & TtT & TtG & TtB & TtR \\
\hline Sum [m2] & 4612,2 & 337,75 & 215888,24 & 19082,68 & 6096,93 & 653,16 \\
\hline Change [\%] & 1,21 & 0,09 & 56,44 & 4,99 & 1,59 & 0,17 \\
\hline
\end{tabular}

Table 4. Quantification of 'from-to' land-cover change. $G=$ grassland, $\mathrm{B}=$ bare soil, $\mathrm{T}=$ Trees, $\mathrm{R}=$ Road. E.g.: $\mathrm{GtB}=$ Grassland to Bare soil

\subsection{Topographical change}

Topographical change is visualized in figure 4, upper right panel. Volumetric changes (in $\mathrm{m}^{3}$ ) are represented in three classes, 1. Removal of material (in red), no change (in yellow) and deposition of material (in green). The resulting patterns reflect the landslide dynamics: red colours dominate in the upper scarp section, and alternate with distinct zones of deposition and no change, which suggests slide-like movement, which is in accordance with observations by Jaritz and Marte (2008). Deposition predominates in the toe area of the slide, without interruptions of vast removal and no change areas, suggesting flow-type accumulations to prevail in the lower section of the landslide. Part of the landslide in the lower eastern edge of Figure seems to be re-activated, probably related to undercutting action of the local Weissach river.

\subsection{Above Ground Biomass change}

The AGB is plotted in $\mathrm{kg}$ for individual tree tops in figure 4, upper right panel. Striking is that small trees (biomass $<250 \mathrm{~kg}$ ) predominantly occur on or close to the lower depositional toe of the landslide, along the edges of forest stands and at canopy openings, probably due to regrowth between 2006 and 2012 . Trees with biomass $>1000 \mathrm{~kg}$ occur mainly in the middle of forest stands and are not affected by the landslide.

\subsection{Combined effects of landslides}

The combined results of the LCC, topographical and biomass change show patterns that align well with the behaviour of large landslides. DEM differencing (figure 4, panel $\mathrm{B}$ and $\mathrm{C}$ ) illustrate that that the landslide is dominated by removal, caused by 'slide-type' movements in the upper scar section, in contrast to the lower section, which indicates 'flow-type' depositional processes. This pattern is reflected in the LCC analysis, because deposition into forested area occurs in the lower toe area, without causing total removal of trees. In total, the forest area slightly increased by $0.86 \%$ compared to 2006 , while biomass decreased $-8.3 \%$. Figure 4, panel A (top-left) illustrates the details and dynamic LCC on the landslide body, in contrast to the relatively stable forested LCC outside the landslide.

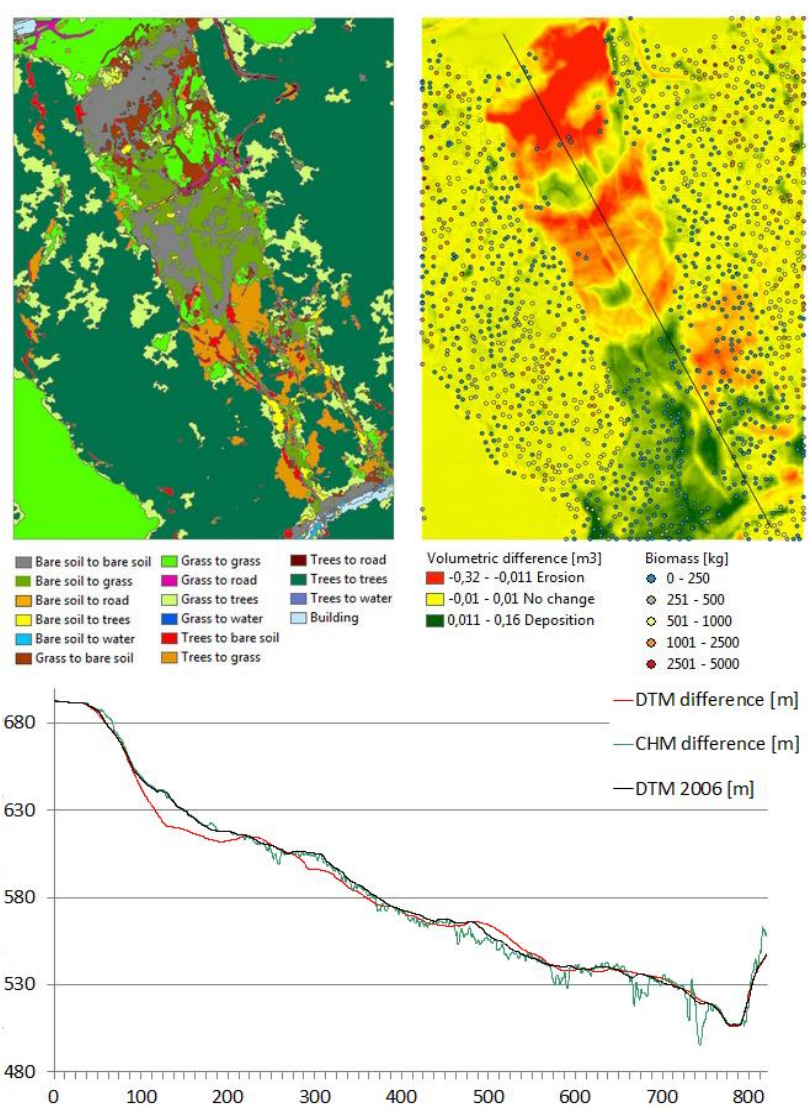

Figure 4. A, upper left panel: 'from-to' classification results of LCC. B, upper right panel: topographical change and AGB for individual tree tops. C, lower panel: topographical cross-section visualizing DTM differences.

\section{DISCUSSION}

Although the quality of the LiDAR data and orthophotos is high, the differences in point densities and the applied filtering and interpolation techniques may cause error propagation in the synergy approach and thus in the resulting LCC. However, elevation differences measured from 50 fixed objects has shown that elevation differences remain below $30 \mathrm{~cm}$. In an active large landslide this is not seen as a major problem.

The synergy of elevation and spectral information to improve segmentation and classification has resulted $18-25 \%$ higher classification accuracies than results based on the single datasets alone. Three distinct errors were detected, related to shadows and LiDAR-based confusion between LC classes. Although synergy solved most of the errors, it remains unsure in a dynamic landslide area, what the effect of time differences between the orthophotos and LiDAR information is.

The orthophotos allow detailed validation of LCC, however, field validation could improve the accuracy assessment of especially AGB; understory, alignment of tree tops on sloping areas and other tree growth specific conditions may hamper exact AGB biomass estimates. In addition, full understanding of the mechanism of landslide dynamics and its combined effects to the landscape, requires some level of field inspection.

The transferability of the workflow to larger areas has great potential, however, VHR datasets require efficient computing 
power, which implies that cloud computing facilities seems a logical future step.

\section{CONCLUSION}

The synergy of orthophotos and LiDAR-based information improved the object-based segmentation and classification results of LCC. Three types of classification errors (shadow effects, small open spots in the forest and LiDAR-based errors) were removed, by using spectral, DTM and CHM information, which increased LCC accuracies by $18 \%$ (for 2016) and 26\% (for 2012). Detailed patterns of stable areas and areas with removal and deposition of material were detected on the landslide, which likely correlate to slide-type and flow-type processes. LCC are most dynamic within the landslide area; major changes occurred from grassland to trees, from bare soil to grassland and from trees to grassland, while the surrounding forested areas remained unchanged.

\section{ACKNOWLEDGEMENTS}

Funding was awarded by the Computational Geo-Ecosystem group of the Institute for Biodiversity and Ecosystem Dynamics (IBED) of the University of Amsterdam. The Land Vorarlberg (www.Voralberg.at) has kindly allowed us to use geographical datasets, orthophotos and LiDAR data, available from the VOGIS repository. The GIS-studio (www.GIS-studio.nl) of the University of Amsterdam is thanked for computational support.

\section{REFERENCES}

Aguirre-Gutiérrez, J., Seijmonsbergen, A. C., \& Duivenvoorden, J. F., 2012. Optimizing land cover classification accuracy for change detection, a combined pixelbased and object-based approach in a mountainous area in Mexico. Applied Geography, 34, 29-37.

Anders, N., Seijmonsbergen, A., and Bouten, W., 2013. Geomorphological change detection using object-based feature extraction from multi-temporal lidar data. Geoscience and Remote Sensing Letters, IEEE, 10(6):1587-1591.

Congalton, R. G., 1991. A review of assessing the accuracy of classifications of remotely sensed data. Remote Sensing of Environment, 37(1):35-46.

Desclee, B., Bogaert, P., and Defourny, P., 2006. Forest change detection by statistical object-based method. Remote Sensing of Environment, 102(1):1-11.

Eisank, C., Smith, M., and Hillier, J., 2014. Assessment of multiresolution segmentation for delimiting drumlins in digital elevation models. Geomorphology, 214:452-464.

Esch, T., Thiel, M., Bock, M., Roth, A., \& Dech, S., 2008. Improvement of image segmentation accuracy based on multiscale optimization procedure. IEEE Geoscience and Remote Sensing Letters, 5(3), 463-467.

Friebe, J. (2007). Geologie der Osterreichischen bundeslander vorarlberg. Geologische Bundesanstalt, Wien, page 154.

James, L. A., Hodgson, M. E., Ghoshal, S., and Latiolais, M. M., 2012. Geomorphic change detection using historic maps and DEM differencing: The temporal dimension of geospatial analysis. Geomorphology, 137(1):181-198.
Jaritz,W., Marte, R., 2008. 75 Jahre Sanierung Großhangbewegung Doren (Vorarlberg) - Ungleiches Ringen zwischen Natur und Technik? Moser/Jaritz Ziviltechniker GmbH. http://mediatum.ub.tum.de/doc/1138083/1138083.pdf

Lahousse, T., Chang, K. T., \& Lin, Y. H., 2011. Landslide mapping with multi-scale object-based image analysis-a case study in the Baichi watershed, Taiwan. Natural Hazards and Earth System Sciences, 11(10), 2715-2726.

Latypov, D., 2002. Estimating relative lidar accuracy information from overlapping flight lines. ISPRS Journal of Photogrammetry and Remote Sensing, 56(4):236-245.

Li, X., Cheng, X., Chen, W., Chen, G., \& Liu, S., 2015. Identification of forested landslides using LiDar data, objectbased image analysis, and machine learning algorithms. Remote Sensing, 7(8), 9705-9726.

Machala, M. and Zejdova, L., 2014. Forest mapping through object-based image analysis of multispectral and lidar aerial data. Eur.J.Remote Sens, 47:117-131.

Maier, B., Tiede, D., \& Dorren, L.K.A., 2006. Assessing mountain forest structure using airborne laser scanning and landscape metrics. Salzburg: Int Archives Photogrammetry Remote sensing Spatial Information Science XXXVI-4/C42.

Mucher, C., Roupioz, L., Kramer, H., Bogers, M., Jongman, R., Lucas, R., Kosmidou, V., Petrou, Z., Manakos, I., and PadoaSchioppa, E., 2015. Synergy of airborne lidar and worldview-2 satellite imagery for land cover and habitat mapping. International Journal of Applied Earth Observation and Geoinformation, 37:48-55.

Muukkonen, P., \& Heiskanen, J., 2005. Estimating biomass for boreal forests using ASTER satellite data combined with standwise forest inventory data. Remote Sensing of Environment, 99(4), 434-447.

Parent, J. R., Volin, J. C., and Civco, D. L., 2015. A fullyautomated approach to land cover mapping with airborne lidar and high resolution multispectral imagery in a forested suburban landscape. ISPRS Journal of Photogrammetry and Remote Sensing, 104:18-29.

Wang, L., Sousa, W. P., \& Gong, P., 2004. Integration of object-based and pixel-based classification for mapping mangroves with IKONOS imagery. International Journal of Remote Sensing, 25(24), 5655-5668.

Wheaton, J. M., Brasington, J., Darby, S. E., and Sear, D. A., 2010. Accounting for uncertainty in dems from repeat topographic surveys: improved sediment budgets. Earth Surface Processes and Landforms, 35(2):136-156.

Wulder, M. A. and Seemann, D., 2003. Forest inventory height update through the integration of lidar data with segmented landsat imagery. Canadian Journal of Remote Sensing, 29(5):536-543.

Zhou, W., Troy, A., and Grove, M., 2008. Object-based land cover classification and change analysis in the Baltimore metropolitan area using multi-temporal high resolution remote sensing data. Sensors, 8(3):1613-1636. 